\title{
Dipyridamole in heart failure due to dilated cardiomyopathy: A pilot study
}

\author{
Francesco Stea, \\ Kálmán Havasi', Rosa Sicari, \\ Zoltán Rózsavölgyi², \\ Maria Aurora Morales, \\ Attila Somfay ${ }^{2}$, \\ Eugenio Picano, \\ Albert Varga ${ }^{1}$
}

Institute of Clinical Physiology, National Research Council, Pisa, Italy, ${ }^{l}$ Second Departments of Medicine and Cardiology Center and ${ }^{2}$ Pulmonology, University of Szeged, Szeged, Hungary

\section{INTRODUCTION}

Heart failure (HF) is a major cause of morbidity and mortality ${ }^{[1,2]}$ so that the understanding of its pathophysiology is crucial to develop new therapeutic strategies. In HF, elevation of plasma adenosine is present. ${ }^{[3]}$ Adenosine exerts protective actions in the failing heart. ${ }^{[4,5]}$ Increased levels may be a compensatory mechanism, and a further elevation might be beneficial. ${ }^{[6]}$ Modulation of the

\section{Address for correspondence:}

Dr. Francesco Stea, Institute of Clinical Physiology, National

Research Council, Via Moruzzi 1, 56124 Pisa (LI), Italy.

E-mail: francescostea@inventati.org

\begin{tabular}{|l|l|}
\hline \multicolumn{2}{|c|}{ Access this article online } \\
\hline Quick Response Code: & Website: \\
\hline & www.pnrjournal.com \\
\cline { 2 - 2 } & \\
\hline
\end{tabular}

myocardial adenosine system may be a novel therapeutic target. ${ }^{[7]}$

Dipyridamole (DIP) is an inhibitor of the adenosine transporter that increases adenosine levels. ${ }^{[8]}$ DIP therapy has improved symptoms, exercise capacity, and left ventricular (LV) function in observational, small studies on patients with HF; ${ }^{[9-11]}$ the PRoFESS study for secondary prevention of stroke observed a reduction in $\mathrm{HF}$ in the arm randomized to acetylsalicylic acid (ASA) plus DIP as compared to the one randomized to clopidogrel. ${ }^{[12]}$

This is an open access article distributed under the terms of the Creative Commons Attribution-NonCommercial-ShareAlike 3.0 License, which allows others to remix, tweak, and build upon the work non-commercially, as long as the author is credited and the new creations are licensed under the identical terms.

For reprints contact: reprints@medknow.com

How to cite this article: Stea F, Havasi K, Sicari R, Rózsavölgyi Z, Morales MA, Somfay A, et al. Dipyridamole in heart failure due to dilated cardiomyopathy: A pilot study. J Pharm Negative Results 2016;7:46-52. 
Stea, et al.: Dipyridamole in dilated cardiomyopathy

The present pilot study was designed as a prospective, double-blind, parallel group, randomized trial to investigate the effects of a combination of DIP and ASA versus ASA alone on dyspnea, LV function, and exercise tolerance in patients with dilated cardiomyopathy (DCM).

\section{MATERIALS AND METHODS}

\section{Study patients}

DCM patients have been enrolled among those referring to the outpatient clinic of the Department of Internal Medicine for care and follow-up of mild to moderate HF. Medical history was collected, and all participants underwent an office examination. The subjects were specifically asked about limitations of physical activity, symptoms, dyspnea and discomfort during exertion, and status at rest. They were classified according to the New York Heart Association (NYHA) Functional Classification. ${ }^{[13]}$

Inclusion criteria were a global moderate to severe LV dysfunction (ejection fraction [EF], <40\% by biplane area-length method on resting echocardiogram) but no history of ischemic heart disease and angiographically normal coronary arteries (coronary angiogram performed prior to enrollment); NYHA Class II despite optimal medical therapy; clinical stability, defined as no change in therapy or symptoms and no hospital admission in the preceding 6 weeks; willingness to join the program. Exclusion criteria were symptomatic peripheral arterial disease, neoplastic disease, significant comorbidities reducing life expectancy to $<1$ year, serum creatinine $>130 \mu \mathrm{mol} / \mathrm{L}$, technically poor acoustic window precluding satisfactory imaging of $\mathrm{LV}$, inability to give informed consent, and contraindications to DIP therapy.

Patients were randomized to receive add-on, 6-month therapy either with ASA, $25 \mathrm{mg}$ twice daily, or with ASA $25 \mathrm{mg}$ plus slow-release DIP $200 \mathrm{mg}$ twice daily (ASA + DIP). Medical therapy remained unchanged during the study. Both patients and investigators were unaware of the treatment allocation. The subjects were examined at baseline, after 3 months, and after completion of the 6-month period.

The investigation complies with the principles outlined in the Declaration of Helsinki. It was approved by the Local Ethics Committee, and all patients provided a written informed consent to participate.

\section{Blood samples}

A blood sample was taken from the antecubital vein on each morning of the examination days, after an overnight fasting, for initial characterization of the study population and follow-up.

\section{Echocardiography}

Transthoracic echocardiographic studies were performed with a Toshiba Aplio ultrasound device (Toshiba Medical Systems Europe, Zoetermeer, Netherlands) equipped with 2.5-3.5 MHz phased-array sector scan probe (S3-S8 or V3-V7) and with the second harmonic technology. All standard echocardiographic views were obtained when possible. Atrial diameters were measured, and atrial volume was calculated by the prolate ellipse method, and then indexed to body surface area. LV end-diastolic and end-systolic diameters were measured from the M-mode trace obtained by parasternal long axis view. LV volumes were measured, and EF obtained by two-dimensional and four-chamber view using biplane area-length method, according to the recommendations of the European Association of Echocardiography. ${ }^{[14]}$ LV mass was calculated by the Devereux formula ${ }^{[15]}$ and indexed to body surface area. Mitral regurgitation was assessed semiquantitatively (from 1 to 4) by color flow Doppler. Mitral inflow pattern at the tips level was measured and $\mathrm{E} / \mathrm{A}$ ratio computed.

\section{Six-minute walk test}

The 6-min walk test (6MWT) was performed according to the American Thoracic Society guidelines. ${ }^{[16]}$ Briefly, all patients were instructed to cover the greatest distance possible on a level hallway during the allotted time at a self-determined walking speed, pausing to rest as needed, and the total distance in meters was recorded. Pulse oxygen saturation was measured by means of a forehead probe connected to an oximeter (Nellcor N-595, Puritan Bennett, Pleasanton, CA, USA). Dyspnea at the end of the 6MWT was self-evaluated by means of Borg scale that rates dyspnea perception and overall fatigue of breathing from 0 (nothing at all) to 10 (very severe). ${ }^{[17]}$

\section{Statistical analysis}

Continuous variables in this analysis are expressed as median (25-75 th percentile) and Mann-Whitney U-test was used to compare the characteristics between the two groups. Differences in categorical variables were compared by the Fisher's exact test. General linear model ANOVA for repeated measures was used to evaluate the difference in changes in time between the two arms. A $P<0.05$ was deemed significant. SPSS software, version 17.0.1 (SPSS Inc., Chicago, IL, USA) was used to perform all statistical analyses.

\section{Sample size calculation}

NYHA class, EF, meters walked at the 6MW', and Borg scale after the test were the variables used to calculate an 
adequate sample size for a possible larger trial, on the basis of the results of the present preliminary study. Clinically relevant changes were considered. Average difference of 1 in NYHA classes, an absolute 5\% variation in EF, $50 \mathrm{~m}$ at the 6MWT, and 1 point in the Borg scale. A statistical power of $90 \%$ with an alpha error of $5 \%$ was set.

\section{RESULTS}

The analysis was performed after the $21^{\text {st }}$ recruited patient completed the 6-month follow-up period. Two of the subjects did not complete the study, dropping after the baseline visit and before randomization: One for unwillingness to continue, the other due to relapse of gynecological cancer. No participant reported serious adverse events during the intervention. Nineteen patients formed the final sample.

Eleven patients received ASA alone; eight in combination with DIP. In Table 1, the baseline clinical characteristics are reported. Table 2 shows echocardiographic parameters. Body weight and biochemical parameters did not differ between arms at any time point, neither changed over time (all $P=$ not significant).

Both groups showed an improvement in exertional dyspnea of daily life, i.e. a downward shift in NYHA class, without differences between the two treatment arms. After 6 months, patients were $n=6 / 5 / 0 / 0$ for NYHA Classes I/ II $/$ III /IV in the ASA arm, $n=4 / 3 / 1 / 0$ in the ASA + DIP arm [Figure 1].

EF increased significantly in both groups (from 34 [28-35\%] to 40 [32-46\%] for ASA, from 32.5 [25.75-34\%] to 36 [31.5-46\%] for ASA + DIP at the end of the study), without differences between arms [Figure 2]. The change was driven by a decrease in LV end-systolic diameter $(P=0.025)$ and volume $(P=0.016)$, while end-diastolic diameter and volume did not change ( $P=0.81$ and $P=0.64$, respectively).

All patients were able to sustain the 6MWT. Pulse oxygen saturation remained normal (94-99\%) for all subjects at all times, before and after the test. No change in exercise capacity and perceived exertion, measured, respectively, as meters walked, and points in the Borg scale was observed [Figures 3 and 4].

On the basis of the mean values and variability of the chosen outcomes as they were measured in our study population, the sample size to detect meaningful differences in time and between arms was computed as a minimum of 8 subjects per arm for NYHA class, 17 for

\begin{tabular}{|c|c|c|c|}
\hline & ASA & $A S A$ + DIP & $P$ \\
\hline & $n=11$ & $n=8$ & \\
\hline Sex, M/F & $8 / 3$ & $6 / 2$ & 1.00 \\
\hline Age, years & $55.7(46.6-60.9)$ & $59.6(55.0-64.5)$ & 0.25 \\
\hline $\begin{array}{l}\text { Time since } \\
\text { diagnosis, months }\end{array}$ & $20(11-72)$ & $24(11-35)$ & 0.78 \\
\hline Hypertension, Y/N & $6 / 5$ & $5 / 3$ & 1.00 \\
\hline Diabetes, Y/N & $4 / 7$ & $4 / 4$ & 0.66 \\
\hline \multicolumn{4}{|l|}{ Therapy, Y/N } \\
\hline ACE-i or ARB & $10 / 1$ & $8 / 0$ & 1.00 \\
\hline Beta-blockers & $11 / 0$ & $8 / 0$ & - \\
\hline Diuretics & $9 / 2$ & $8 / 0$ & 0.49 \\
\hline Digitalis & $3 / 8$ & $1 / 7$ & 0.60 \\
\hline Nitrates & $1 / 10$ & $1 / 7$ & 1.00 \\
\hline CCB & $3 / 8$ & $6 / 2$ & 0.07 \\
\hline ASA & $5 / 6$ & $5 / 3$ & 0.65 \\
\hline Statin & $5 / 6$ & $3 / 5$ & 1.00 \\
\hline BMI, kg/m² & $26.9(24.5-30.6)$ & $29.1(25.0-31.8)$ & 0.44 \\
\hline $\mathrm{Na}, \mathrm{mEq} / \mathrm{L}$ & $141(140-141.75)$ & $143(140.75-143.5)$ & 0.09 \\
\hline $\mathrm{K}, \mathrm{mEq} / \mathrm{L}$ & $4.55(4.3-4.85)$ & $4.20(3.80-4.48)$ & 0.21 \\
\hline Creatinine, $\mathrm{mmol} / \mathrm{L}$ & $75(64.5-87)$ & $83(78-91)$ & 0.17 \\
\hline $\mathrm{Hb}, \mathrm{g} / \mathrm{dl}$ & $14.0(13.15-14.65)$ & $14.5(14.5-14.6)$ & 0.41 \\
\hline $\begin{array}{l}\text { Total cholesterol, } \\
\mathrm{mmol} / \mathrm{L}\end{array}$ & $5.18(4.94-6.40)$ & $5.10(4.27-5.85)$ & 0.46 \\
\hline \multicolumn{4}{|l|}{ 6-min walk test } \\
\hline Meters walked & $390(366.5-510)$ & 367.5 (339.5-392.5) & 0.25 \\
\hline Borg scale & $2(1-4.5)$ & $2.5(1-5)$ & 0.87 \\
\hline
\end{tabular}

Variables are median (25-75\%) or dichotomized. ACE-i: Inhibitors of the angiotensin converting enzyme, ARB: Angiotensin receptor blocker, ASA: Acetylsalicylic acid, BMI: Body mass index, CCB: Calcium channel blockers, DIP: Dipyridamole, $\mathrm{Hb}$ : Hemoglobin, M/F: Male/female, Y/N:Yes/no

Table 2: Echocardiographic parameters at baseline

\begin{tabular}{|c|c|c|c|}
\hline & $\begin{array}{l}\text { ASA } \\
n=11\end{array}$ & $\begin{array}{c}\text { ASA + DIP } \\
n=8\end{array}$ & $P$ \\
\hline $\begin{array}{l}\text { End-diastolic LV } \\
\text { diameter, } \mathrm{mm}\end{array}$ & $69(63.5-75)$ & $69(67.5-71.5)$ & 0.87 \\
\hline $\begin{array}{l}\text { End-systolic LV } \\
\text { diameter, mm }\end{array}$ & $60(52.5-63.5)$ & $58(55-59.5)$ & 0.87 \\
\hline $\begin{array}{l}\text { End-diastolic LV } \\
\text { volume, } \mathrm{ml}\end{array}$ & $242(216-300)$ & $245(232-267.5)$ & 0.68 \\
\hline $\begin{array}{l}\text { End-systolic LV } \\
\text { volume, ml }\end{array}$ & $177(132.5-189.5)$ & $163(151-171)$ & 0.84 \\
\hline Ejection fraction, \% & $34(28-35)$ & $32.5(25.75-34)$ & 0.43 \\
\hline Left ventricular mass, $\mathrm{g}$ & $201(200-231)$ & $257(202-290)$ & 0.46 \\
\hline $\begin{array}{l}\text { Left ventricular mass } \\
\text { index, } \mathrm{g} / \mathrm{m}^{2}\end{array}$ & $115(102-121)$ & $123(101-144)$ & 0.51 \\
\hline $\mathrm{E} / \mathrm{A}$ & $0.96(0.77-1.46)^{*}$ & $0.59(0.50-1.61)^{\dagger}$ & 0.71 \\
\hline Mitral regurgitation, 1-4 & $2(1.5-2)$ & $1.5(1-2)$ & 0.27 \\
\hline Left atrial volume, $\mathrm{ml}$ & $70(63-102)$ & $77(68-92)$ & 0.77 \\
\hline $\begin{array}{l}\text { Left atrial volume } \\
\text { index, } \mathrm{ml} / \mathrm{m}^{2}\end{array}$ & $41(28-56)$ & $42(38-46)$ & 0.92 \\
\hline
\end{tabular}




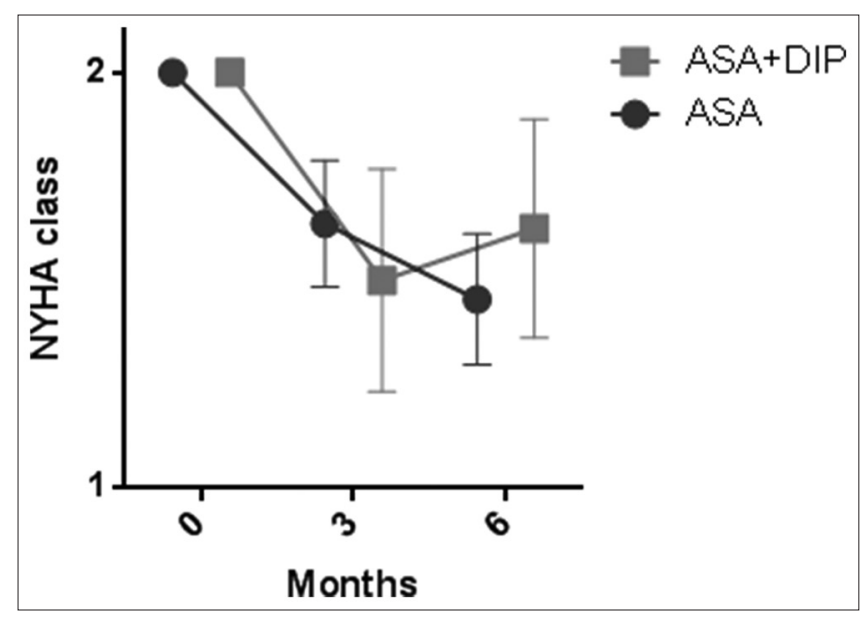

Figure 1: New York Heart Association class. Mean values; error bars are \pm standard error of the mean. Time effect: $P=0.005$. Time $\mathrm{x}$ therapy: $P=0.56$

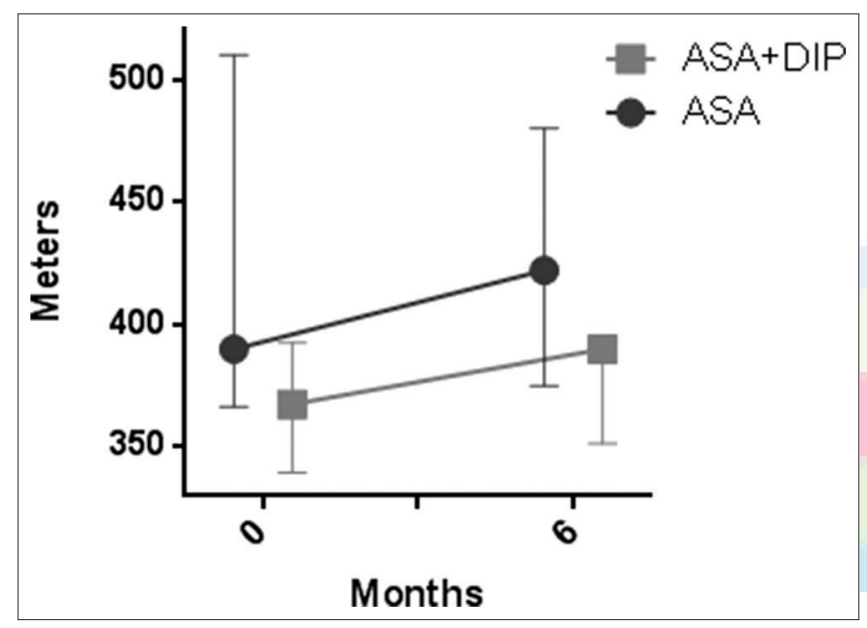

Figure 3: Meters walked at the 6-min walk test. Median values; error bars are $25-75 \%$. Time effect: $P=0.69$. Time $\mathrm{x}$ therapy: $P=0.69$

EF, 12 for the 6MW'T, and 12 for the Borg scale. Allowing a comparable drop-out rate ( 2 out of $21 ; 9.5 \%$ ), the number of subjects to recruit would increase to $9,19,14$, and 14 , respectively.

\section{DISCUSSION}

This pilot study was designed to investigate the clinical effect of a 6-month course of either ASA alone, or the commercially available combination of ASA and extended-release DIP, in patients with HF due to DCM. So far, the analyses did not show any significant difference between the two groups as regards to changes in clinical and echo parameters and exercise capacity. However, it has to be acknowledged that our sample is underpowered. On the basis of these preliminary data, a properly sized trial adequately powered HF sample to test clinical and outcome end-points and detect any significant variation in time and

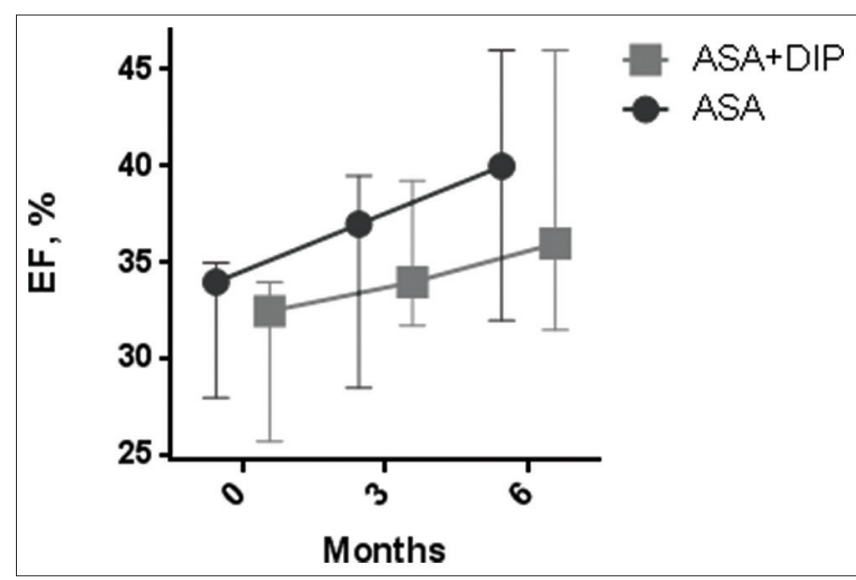

Figure 2: Ejection fraction. Median values; error bars are $25-75 \%$. Time effect: $P=0.003$. Time $\mathrm{x}$ therapy: $P=0.83$

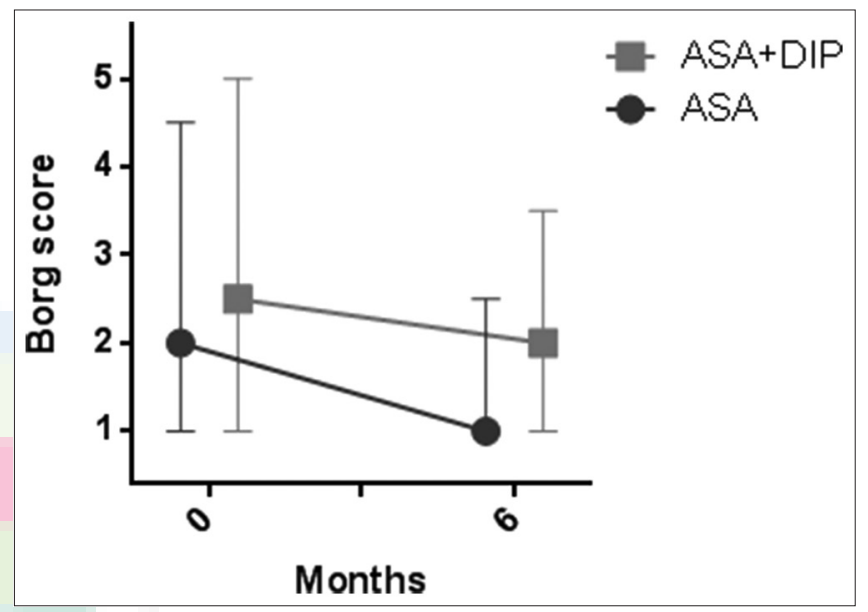

Figure 4: Borg score after the 6-min walk test. Median values; error bars are $25-75 \%$. Time effect: $P=0.15$. Time $x$ therapy: $P=0.66$

difference between arms would need the recruitment of at least 38 patients.

\section{Rationale of the study}

Adenosine, produced in cardiomyocytes and in endothelial cells, is known to be cardioprotective by targeting different receptors subtypes (A1, A2A, A2B, and A3). ${ }^{[4]}$ Adenosine attenuates the release of catecholamines, $\beta$-adrenoceptor-mediated myocardial hypercontraction, and calcium overload via A1 receptors. It also increases coronary blood flow and inhibits platelet and leukocyte activation via A2 receptors. Adenosine may exert antifibrotic and antiapoptotic effects. ${ }^{[18,19]}$ Plasma adenosine levels are elevated ${ }^{[3]}$ and receptors are upregulated ${ }^{[20]}$ in patients with HF. This led to hypothesize that the increase in adenosine could represent a compensatory mechanism and to speculate on a possible therapeutic use of this molecule. However, due to the necessity of intravenous administration, to extremely short half-life, and to severe side effects, exogenous adenosine as such has no role in chronic therapies. 
DIP is a pyridopyrimidine compound with a complex and still partially unclear mechanism of action. Among its effects - whose most known is the antiplatelet action - it inhibits adenosine reuptake thereby increasing the local and plasmatic concentration of adenosine; it may have cardiac pro-angiogenic ${ }^{[2]}$ as well as direct anti-inflammatory properties. At present, DIP has two main clinical indications: (1) Intravenous high doses formulation for stress testing for coronary artery disease, an effect linked to the coronary vasodilatory effect; ${ }^{[2]}$ (2) oral low dose, extended-release formulation, in combination with ASA, for secondary prophylaxis of stroke. ${ }^{[23]}$

Clinical research concerning adenosine has usually looked for adenosine donors or receptor agonists. DIP has a limited marketing appeal for novel applications, since it is low-cost and patent-free, yet it has significant advantages when compared to new molecules. The drug has been on the market for 50 years and has an undisputed safety record, both at high intravenous doses and at low oral doses. It was largely used for the treatment of myocardial infarction in the 1960s and 70s, in the absence of any evidence-based proof of efficacy but with the robust empiric support of safety.

Some studies suggest that DIP therapy, resulting in an increase of adenosine levels, may be beneficial in HF with ischemic heart disease. ${ }^{[24-27]}$ Chronic oral administration of sustained-release DIP has been reported to improve symptoms, exercise capacity, and LV function in patients with HF. ${ }^{[9-11]}$ These studies are, however, limited by small sample size, variable dose range, heterogeneity of population, observational design, lack of control group, nonrandomized allocation of treatment, or absence of blinding procedures.

On the other hand, the PRoFESS study - a large, randomized clinical trial whose main aim was to compare clopidogrel to the combination of ASA and DIP in secondary prevention of stroke - observed, as a tertiary end-point, a significant, unexpected, $30 \%$ reduction in the risk of new or worsening HF with ASA plus DIP. ${ }^{[12]}$ The explanation of all these findings remains unsettled, but it may relate to the long-term positive effects of endogenous adenosine accumulation, possibly extended through an angiogenic, anti-inflammatory, anti-fibrotic, and anti-apoptotic effect. ${ }^{[28,29]}$

\section{Comparison with previous studies}

In this ad hoc, pilot study, both the ASA and the ASA + DIP groups increased in EF and decreased in NYHA. The change occurred in the ASA group is an unexpected result. It could be attributable to a combination of placebo effect, regression to the mean, and better adherence to therapies in a drug trial setting. Moreover, studies on chronic HF should ideally be performed on "stable" patients, both from a clinical and pharmacological standpoint. Previous small-scale studies on DIP and HF do not mention specific periods of "stability" to enter the study; in the European HF guidelines, a stable patient is defined as having had no change in signs or symptoms for a month, but changes in therapy are not cited. ${ }^{[2]}$ In the absence of a univocal definition of "stability," one of the inclusion criteria of the present study was 6 weeks without changes in therapy or symptoms, but such a time could possibly not be enough, and in the study period patients could have shown a delayed benefit from drug therapies modified shortly before the term.

In the present study, the positive finding of the improvement found in all key variables before and after DIP therapy turned into a neutral finding when the results in the control group - not available in the design of previous positive reports ${ }^{[9,11]}$ - were considered.

In former studies, benefits were already apparent also in shorter times, with lower DIP doses, or with a comparable number of subjects. It has to be pointed out, however, that our investigation enrolled patients with DCM, excluding those with HF due to ischemic causes, while other dealt with mixed populations ${ }^{[9,11,12]}$ or, on the contrary, specifically with ischemic patients. ${ }^{[10,26,27]}$ These latter could particularly benefit from the known effect of DIP on myocardial perfusion and coronary collateralization that is expected to play a minor role in DCM.

A feature only partially explained by the time the other studies were performed is the difference in therapies. There is heterogeneity in the use of diuretics, digitalis, aldosterone antagonists, calcium channel blockers, nitrates, and anticoagulants; also beta-blockers, statins, and antiplatelet drugs are used unevenly, even in patients with myocardial ischemia. Some drugs, in particular calcium-antagonists, might have ancillary effect increasing plasma adenosine levels. ${ }^{[30]}$ This could represent a confounder; in our study, patients had been on optimal medical therapy for at least 6 weeks, and amlodipine was the only calcium-channel blocker employed.

Adenosine receptor polymorphisms can affect coronary flow reserve response during DIP stress testing; ${ }^{[11]}$ differences in the genetic background could have influenced the response in our investigation, which dealt with small numbers and a particular ethnic group. ${ }^{[2,33]}$

\section{Study limitations}

The present study includes ASA in both treatment arms. This antiplatelet drug is not a standard therapy in HF, since 
Stea, et al.: Dipyridamole in dilated cardiomyopathy

it has no evidence of benefit, and although extensively used may raise harm concerns unless appropriately indicated. ${ }^{[1]}$ Moreover, a proportion of the subjects, similar in the two groups, was already taking ASA before entry. We cannot exclude a masking effect on the benefits of DIP. A study about prevention of cerebral ischemia with ASA (although at high dose) found no significant difference in HF occurrence between subjects taking also DIP and those who were not. ${ }^{[34]}$ Furthermore, in the PRoFESS trial which is an important background to our study, the results were analyzed after a median follow-up of 2.5 years, ${ }^{[12]}$ suggesting that the effects on HF may take longer than 6 months to show.

Additional benefits of DIP are often attributed to its anti-inflammatory properties. We acknowledge that measuring inflammatory blood markers and relating them and their changes to clinical effects would have been interesting. ${ }^{[35]}$ Furthermore, as plasma adenosine was not measured, it is not known if the same dose of DIP turned out in comparable increases in all patients of the ASA + DIP arm, which were only eight. This introduces the most obvious limitation of the study: The small sample size. It was basically due to lack of external funding, which led to restrictions in recruitment but also to the obvious advantage of a nonprofit, curiosity-driven investigation without the possible bias due to industry funding. The stringent selection criteria excluding patients with ischemic disease, the randomized, double-blind, and placebo-controlled study design allowed to obtain a methodologically sound information.

\section{CONCLUSION}

This pilot study did not confirm, so far, a beneficial role on symptoms, exercise capacity or systolic function of DIP plus ASA, compared to the latter drug alone, in DCM patients. The findings are however to be considered with caution. The data have barely enough statistical power to adequately test the NYHA outcome only - a rather subjective measure.

The lack of benefit at this point may appear in contrast with previous studies, but the strict inclusion criteria, the randomized, double-blind design, and the use of well-established clinical end-points give strength to these preliminary findings. The present study could guide other investigators in designing new trials with larger samples - but well within the recruitment capability of a single center - and/or longer follow-ups allowing changes in heart function and hemodynamics to become effective, to shed light on a possible role of DIP in the management of nonischemic HF.

\section{Financial support and sponsorship \\ Nil.}

\section{Conflicts of interest}

There are no conflicts of interest.

\section{REFERENCES}

1. Yancy CW, Jessup M, Bozkurt B, Butler J, Casey DE Jr, Drazner MH, et al. American College of Cardiology Foundation; American Heart Association Task Force on Practice Guidelines. 2013 ACCF/ AHA guideline for the management of heart failure: A report of the american college of cardiology foundation/american heart association task force on practice guidelines. J Am Coll Cardiol 2013;62:e147-239.

2. McMurray JJ, Adamopoulos S, Anker SD, Auricchio A, Böhm M, Dickstein K, et al. ESC Committee for Practice Guidelines. Esc guidelines for the diagnosis and treatment of acute and chronic heart failure 2012: The task force for the diagnosis and treatment of acute and chronic heart failure 2012 of the european society of cardiology. Developed in collaboration with the heart failure association (hfa) of the esc. Eur Heart J 2012;33:1787-847.

3. Funaya H, Kitakaze M, Node K, Minamino T, Komamura K, Hori M. Plasma adenosine levels increase in patients with chronic heart failure. Circulation 1997;95:1363-5.

4. Hori M, Kitakaze M. Adenosine, the heart, and coronary circulation. Hypertension 1991;18:565-74.

5. Picano E, Abbracchio MP. Adenosine, the imperfect endogenous anti-ischemic cardio-neuroprotector. Brain Res Bull 2000;52:75-82.

6. Picano E, Morales MA, del Ry S, Sicari R. Innate inflammation in myocardial perfusion and its implication for heart failure. Ann N Y Acad Sci 2010;1207:107-15.

7. Funakoshi H, Zacharia LC, Tang Z, Zhang J, Lee LL, Good JC, et al. A1 adenosine receptor upregulation accompanies decreasing myocardial adenosine levels in mice with left ventricular dysfunction. Circulation 2007;115:2307-15.

8. Sudlow C. What is the role of dipyridamole in long-term secondary prevention after an ischemic stroke or transient ischemic attack? CMAJ 2005;173:1024-6.

9. Kitakaze M, Minamino T, Node K, Koretsune Y, Komamura K, Funaya $\mathrm{H}$, et al. Elevation of plasma adenosine levels may attenuate the severity of chronic heart failure. Cardiovasc Drugs Ther 1998;12:307-9.

10. Akhtar M, Ordovas K, Martin A, Higgins CB, Michaels AD. Effect of chronic sustained-release dipyridamole on myocardial blood flow and left ventricular function in patients with ischemic cardiomyopathy. Congest Heart Fail 2007;13:130-5.

11. Sanada S, Asanuma H, Koretsune $Y$, Watanabe K, Nanto S, Awata N, et al. Long-term oral administration of dipyridamole improves both cardiac and physical status in patients with mild to moderate chronic heart failure: A prospective open-randomized study. Hypertens Res 2007;30:913-9.

12. Sacco RL, Diener HC, Yusuf S, Cotton D, Ounpuu S, Lawton WA, et al. PRoFESS Study Group. Aspirin and extended-release dipyridamole versus clopidogrel for recurrent stroke. N Engl J Med 2008;359:1238-51.

13. Dolgin M. Nomenclature and Criteria for Diagnosis of Diseases of the Heart and Great Vessels. Boston, London: Little, Brown; 1994. p. 253-56.

14. Lang RM, Bierig M, Devereux RB, Flachskampf FA, Foster E, Pellikka PA, et al. American Society of Echocardiography's Nomenclature and Standards Committee; Task Force on Chamber Quantification; American College of Cardiology Echocardiography Committee; American Heart Association; European Association of Echocardiography, European Society of Cardiology. Recommendations for chamber quantification. Eur J Echocardiogr 2006;7:79-108. 
Stea, et al.: Dipyridamole in dilated cardiomyopathy

15. Devereux RB, Alonso DR, Lutas EM, Gottlieb GJ, Campo E, Sachs I, et al. Echocardiographic assessment of left ventricular hypertrophy: Comparison to necropsy findings. Am J Cardiol 1986;57:450-8.

16. ATS Committee on Proficiency Standards for Clinical Pulmonary Function Laboratories. Ats statement: Guidelines for the six-minute walk test. Am J Respir Crit Care Med 2002;166:111-7.

17. Borg G. Perceived exertion as an indicator of somatic stress. Scand J Rehabil Med 1970;2:92-8.

18. Simonis G, Wiedemann S, Joachim D, Weinbrenner C, Marquetant R, Strasser $\mathrm{RH}$. Stimulation of adenosine A2b receptors blocks apoptosis in the non-infarcted myocardium even when administered after the onset of infarction. Mol Cell Biochem 2009;328:119-26.

19. Epperson SA, Brunton LL, Ramirez-Sanchez I, Villarreal F. Adenosine receptors and second messenger signaling pathways in rat cardiac fibroblasts. Am J Physiol Cell Physiol 2009;296:C1171-7.

20. Cabiati M, Caruso R, Verde A, Sabatino L, Morales MA, Del Ry S. Transcriptomic profiling of the four adenosine receptors in human leukocytes of heart failure patients. Biomed Res Int 2013;2013:569438.

21. Torry RJ, O'Brien DM, Connell PM, Tomanek RJ. Dipyridamole-induced capillary growth in normal and hypertrophic hearts. Am J Physiol 1992;262:H980-6.

22. Sicari R, Nihoyannopoulos P, Evangelista A, Kasprzak J, Lancellotti P, Poldermans D, et al. European Association of Echocardiography. Stress echocardiography expert consensus statement--executive summary: European association of echocardiography (EAE) (a registered branch of the ESC). Eur Heart J 2009;30:278-89.

23. Lansberg MG, O'Donnell MJ, Khatri P, Lang ES, Nguyen-Huynh MN, Schwartz NE, et al. American College of Chest Physicians. Antithrombotic and thrombolytic therapy for ischemic stroke: Antithrombotic therapy and prevention of thrombosis, $9^{\text {th }}$ ed: American college of chest physicians evidence-based clinical practice guidelines. Chest 2012;141(Suppl):e601S-e636S.

24. Picano E, Michelassi C. Chronic oral dipyridamole as a 'novel' antianginal drug: The collateral hypothesis. Cardiovasc Res 1997;33:666-70.

25. Figueredo VM, Diamond I, Zhou HZ, Camacho SA. Chronic dipyridamole therapy produces sustained protection against cardiac ischemia-reperfusion injury. Am J Physiol 1999;277:H2091-7.

26. Belardinelli R, Belardinelli L, Shryock JC. Effects of dipyridamole on coronary collateralization and myocardial perfusion in patients with ischaemic cardiomyopathy. Eur Heart J 2001;22:1205-13.

27. Ikeda E, Kasai T, Kajimoto K, Miyauchi K, Kubota N, Kurata T, et al. Dipyridamole therapy improves long-term survival after complete revascularization in patients with impaired cardiac function: A propensity analysis. Circ J 2008;72:1588-93.

28. Peart JN, Headrick JP. Adenosinergic cardioprotection: Multiple receptors, multiple pathways. Pharmacol Ther 2007;114:208-21.

29. Willems L, Ashton KJ, Headrick JP. Adenosine-mediated cardioprotection in the aging myocardium. Cardiovasc Res 2005;66:245-55.

30. Yeung PK, Mosher SJ, Macrae DA, Klassen GA. Effect of diltiazem and its metabolites on the uptake of adenosine in blood: An in-vitro investigation. J Pharm Pharmacol 1991;43:685-9.

31. Andreassi MG, Laghi Pasini F, Picano E, Capecchi PL, Pompella G, Foffa I, et al. Adenosine A2(A) receptor gene polymorphism (1976C>T) affects coronary flow reserve response during vasodilator stress testing in patients with non ischemic-dilated cardiomyopathy. Pharmacogenet Genomics 2011;21:469-75.

32. Tömöry G, Csányi B, Bogácsi-Szabó E, Kalmár T, Czibula A, Csosz A, et al. Comparison of maternal lineage and biogeographic analyses of ancient and modern hungarian populations. Am J Phys Anthropol 2007;134:354-68.

33. Guglielmino CR, Béres J. Genetic structure in relation to the history of hungarian ethnic groups. Hum Biol 1996;68:335-55.

34. Bousser MG, Eschwege E, Haguenau M, Lefaucconnier JM, Thibult N, Touboul D, et al. "AICLA" controlled trial of aspirin and dipyridamole in the secondary prevention of athero-thrombotic cerebral ischemia. Stroke 1983;14:5-14.

35. Del Ry S, Morales MA, Scali MC, Tafi A, Giustarini C, Posteraro F, et al. Effect of concomitant oral chronic dipyridamole therapy on inflammatory cytokines in heart failure patients. Clin Lab 2013;59:843-9. 